\title{
CONTRACTS OF MAKING, VIEWING AND LISTENING: RESEARCHING IN AND THROUGH FILMS
}

\author{
RAM KRISHNA RANJAN*
}


Ram Krishna Ranjan works at the intersection of research, pedagogy and film practice. He is currently a PhD candidate in Artistic Research at HDK-Valand, University of Gothenburg.

\section{Corresponding author:}

Ram Krishna Ranjan

ram.ranjan@akademinvaland.gu.se

HDK-Valand, Vasagatan 50, 41137 Göteborg Sweden

Paper submitted: $28^{\text {th }}$ March 2020

Accepted for Publication: $26^{\text {th }}$ September 2020

Published online: $13^{\text {th }}$ November 2020 


\begin{abstract}
This paper tells the story of Contracts of making, viewing and listening, a 17-minute film that has emerged as part of my ongoing doctoral study in Artistic Research in Film. Taking the Bengal Famine of 1943 as a site-event, the doctoral research focuses on investigating and experimenting with epistemologies and ontologies of expressions emanating from a space of subalternity, especially Dalits. Contracts of making, viewing and listening can be seen as an artistic intervention into Satyajit Ray's Distant Thunder - made in 1973, the film tells the story of effects of the Famine in rural Bengal through the eyes of a Brahmin couple. The artistic intervention was geared towards both critically reading the film from the lens of Dalit consciousness, and to explore ways of writing that critique in the language of the film itself. By retracing the journey of Contracts of making, viewing and listening, this paper focuses on how research is performed in and through the medium of film in this intervention, its multiple conceptual/ material contingencies, and ultimately what it proposes in the context of artistic research.
\end{abstract}

Keywords: The Bengal Famine of 1943, Subaltern, Dalit, Visual intervention, Artistic research in films. 


\section{Introduction}

If I am questioned; if anyone wonders (as happens quite peremptorily) what I 'wanted to say' in a certain poem, I reply that I did not want to say, but wanted to make, and that it was the intention of making which wanted what I said. (Paul Valèry quoted in Gibson, 2015, p. 177)

To create is to understand and to understand is to re-create. (Minh-ha, 1991, p.194)

But what happens when written scholarly utterances in our disciplines are used merely to supplement, comment on, or verbally summarise research performed in the same medium or mode as the subject of the research, that is - in the case of film, television, audiovisual artworks, or internet videos - audiovisually? Indeed, what if the creative production of audiovisual material centrally constitutes the research into audiovisuality? (Grant, 2016)

Artistic research, often further categorized as practice-based research or practice-led research, is yet to reach a settled status; its definition, discourse and framework vary significantly (Candy and Edmonds, 2016). This unsettlement becomes even more obvious when one gets into the quagmire of definitional and differentiation challenges inherent in mobilizing terms such as 'practice-based' and 'practice-led'. As someone who is currently a doctoral candidate in Artistic Research in Film and works at the intersection of pedagogy, theory and practice, I have personally felt a lot more liberated when I have moved away from narrow lanes of definitions and differentiations and embraced some broad and general tenets of artistic research. Here I wish to outline some of these tenets as it will situate and set the parameters for the discussion of my film Contracts of making, viewing and listening in the context of artistic research. At the core of artistic research, as articulated by Candy and Edmonds (2016), is the idea that research and practice should be conceived as interdependent and complementary processes; to what extent primacy is given to practice differs from place to place and project to project. Essentially, artistic research proposes that practice can be both a method and an outcome and moreover, "practice can not know or perceive its outcome" (Bolt, 2004). I would add here that in artistic research, thinking and making are intertwined, or in other words, hyphenated; an extension of this formulation means that it does not propose any fixed chronology or hierarchy between thinking and making. Much of the strength of artistic research (and what makes it exciting), I would argue, comes from this inbetween, ambiguous, fragmented yet composite, and open-ended nature.

Critical scholarship on artistic research in films is still in a nascent stage, but in my understanding the aforementioned tenets remain useful as a starting point. The focus here is research on/about/for/in/thorough film. Even when cross-disciplinary research strategies are mobilized to advance our understandings on any given research topic, the fulcrum of artistic research in film, for me, is the medium of film as a means of investigation. On a cautionary note, this does not automatically imply that methods from other research traditions can't be mobilized. Having said that, what makes artistic research in film exciting for me is the possibility of carrying out the research through film. This particular framing of in and through is very well articulated by The Netherlands Film Academy on their website:

Artistic research in and through cinema means thinking through images and sounds. It means starting from the practice, knowledge and perspectives of filmmaking, and using its accompanying concepts and language. Thus, researching 'in and through' cinema refers to research through the frame, notions and paradigm of the filmmaking practice. The research 'in' revolves around questions of the cinema 
practice itself - spectatorship, perception, storytelling, modes of production, ethics et cetera - while, in addition, research 'through' relates to the use of cinematic conditions and concepts to explore topics and fields beyond cinema - topics such as memory, trauma, archival practices, human relations or identity for example. (Netherlands Film Academy, n.d.)

It is in this context I wish to tell you the story of my film Contracts of making, viewing and listening. This 17-minute-long film has emerged during my ongoing doctoral study in Artistic Research that focuses on the Bengal Famine of 1943. Before I elaborate upon how in Contracts of making, viewing and listening research is performed in and through the medium of film, its multiple conceptual/material contingencies, and ultimately what it proposes in the context of artistic research, the setting under which the work has emerged needs to be spelt out.

\section{Situating the broader research}

Taking the Bengal Famine of 1943 as a site-event, my doctoral research aims to further and experiment with epistemologies and ontologies of expressions that emerge from the space of subalternity, and investigate the possibilities and limits of it in film practices. The main research question that underpins this research is: how do we move images (specifically filmmaking practice) towards subaltern epistemologies and ontologies?

The Bengal Famine of 1943-44, which resulted in nearly five million deaths, is almost universally considered one of the most catastrophic and murderous instances of British coIonial rule in India (Sen, 1981; Sengupta, 2016). The colonial government's policy of diverting agricultural land from food crop to cash crops and prioritising food supplies to its troops at the expense of the general public, contributed significantly to the making of this crisis. Fearing a Japanese invasion of Bengal through Burma, the government further exacerbated the matter by removing surplus stocks of paddy and curtailing boat transport lines in eastern and coastal Bengal. The general scarcity and panic also induced private hoarding and profiteering by some Bengali elites. Even at the height of the famine, the Churchill government continued to prevent food imports. The net result was mass starvation, displacement, death, and chronic disease (Sen, 1981; Sengupta, 2016).

The famine and the crisis ridden years of the 1940s gave rise to much compelling literature and art in Bengal. This response, however, was tinged with anticipation of a post- independence utopia where hunger, suffering, and class conflict would be eradicated. The inequities and complexities of caste, class, and gender in victimization by the famine were overtaken by a generalized and increasingly fervent nationalist sentiment and a renewed anti-colonial agenda. The 'bhadralok' (Bengali elite) were empathetic towards the suffering of the subalterns but only from an intellectual distance. The resulting art and literature didn't fully capture the profound sub-narratives and fault lines of caste, class, and gender that the famine had so brutally exposed (Kaur, 2014).

It is in this context that my research begins with the acknowledgement that any serious engagement with the complexities of the Bengal Famine warrant a reconsideration: analysis and artistic representation of the famine can't stem only from colonial critique; a shift towards situating the famine in terms of subalternity (caste, class, gender, rural-urban divide etc.) must occur. Against this backdrop, my research attempts to advance and engage with the complexities of using subalternity as a framework for understanding the famine.

This artistic research is concerned with subaltern epistemologies and ontologies but a delineation must be made that it's not a project of anthropology, ethnography, oral 
history, subaltern or Dalit ${ }^{1}$ historiography, postcolonial studies or famine studies. Theories and methods from aforementioned fields inform it but practice is a key method of inquiry. Therefore, along with investigation of the Bengal Famine from a subaltern theoretical framework, questions of representation, artistic mediation and image-making are central to the research.

In light of the general omission of subaltern questions, especially Dalits, in the literary and artistic representation of the Bengal Famine, and since my practice is filmmaking, I engaged with existing cinematic works on the Bengal Famine to investigate how the subaltern questions have manifested in these films. If one falls back on conventional paradigms of various stages of a doctoral study, this would qualify as part of 'mapping the field'. However, my aim was not only to provide a close reading of the films but also make critical visual interventions in them to understand how, as a film practitioner, one can reimagine or offer possibilities for different ways of 'mapping the field'. How can I perform research in and through the medium of film itself? I was particularly inspired by Grant's (2016) proposition that performing research through the medium of filmmaking should not be an afterthought. It's not an exercise in discursive translation of existing or new research. Grant (2014) asks "should we be aiming to "translate" the (often unspoken) norms and traditions of written film studies into audiovisual versions, or should we embrace from the outset the idea that we are creating ontologically new scholarly forms?" Accompanying written work can certainly help in situating it in wider research contexts but we should see the film/video as "self-contained performative acts" (Grant, 2016).

\section{Cast(e)ing shadows on Distant Thunder}

Two most prominent films made on the Bengal Famine are Satyjit Ray's Distant Thunder (1973) and Mrinal Sen's In Search of Famine (1981). I have engaged with both of the films and made artistic interventions in them to advance my research. For the purpose of this paper, I am focusing only on my intervention into Distant Thunder, which has been titled Contracts of making, viewing and listening.

Set in the villages of Bengal, Satyajit Ray's film Distant Thunder, based on a short story by Bibhutibhushan Bandopadhyay, examines the effect of the Great Famine of 1943. The film centers on the subjective experiences of a Brahmin ${ }^{2}$ couple - Gangacharan and his wife Ananga, showing their cheerful lives progressively disrupted and affected by the famine. Gangacharan and Ananga have recently moved to a 'low caste' village. Being the only Brahmin in the village, Gangacharan works the honor and respect given to him because of his Brahmin status and enterprisingly assumes the role of a priest, teacher, and a doctor. As the film unfolds, we see the effects of famine - a slight dilution of caste and gender norms observed in the village; worsening of Gangacharan's material situation forcing him to reconsider some of his moral positions; and ultimately the establishment of human values in the face of such a crisis.

The film opens with panoramic shots of the village, lush green paddy fields, a pond with water lilies and silhouetted trees. A particular kind of idealized and romantic notion of the rural is generated from the beginning and the identification of the women with nature is implied on numerous occasions (Pathiraja and Hanan, 2006). The decision to shoot

1 Literally 'ground down' or 'oppressed'; the term was popularized by B.R. Ambedkar and in contemporary India it refers to the preferred political self-identification of social groups belonging to 'ex-untouchable castes'. As per the Hindu caste structure, they were considered to be excluded from the four varnas and therefore the 'lowest castes'. The Indian state, through its constitutional framework, refers to Dalits as the 'Scheduled Castes'. Dalits constitute 17 per cent of the national population. 
the film in colour, to point out the contrast between nature's vivacity and people starving to death elicited surprise as the expectation was that a story of famine will be told in black and white (Robinson, 1989). Atanu Pal of Third Eye, a photography group, writes "...Ray felt that he could establish the aridity of famine more starkly in colour, leaving nothing to the imagination" (Banerjee, 2017). Ray, in his interview with Cineaste magazine, alludes that the famine occurred despite a good harvest and as for his use of colour, he says, "it came straight from author's description - that nature was very lush, that everything was physically beautiful, and, yet, people were dying of hunger" (Gupta and Ray, 1982). If one begins with the understanding that famine occurred despite good harvest it is natural to then enquire the reasons behind the terrible reality of starvation and death of close to five million people. Ray in Distant Thunder does not delve substantially into how the existing inequalities at the time made it worse for people at the margins. Distant Thunder is not an isolated case when it comes to Ray's oeuvre. Long regarded as a humanist director, Ray, in his works, tends to privilege establishment of human values over social critique (Pathiraja and Hanan, 2006). One of the charges levelled against Ray is that he was "less interested in expressing ideas than in communicating emotional experience" (Wood, 1971 as cited in Cooper, 2000, p.2). Ray's humanism was geared towards achieving a universal cinematic language, one that emanates from a particular geography but is made keeping in mind the global audience. Ray himself remarked once that "if you are able to portray universal feelings, universal relations, emotions and character, you can cross certain barriers and reach out to others, even non-Bengalis" (Gupta and Ray, 1982). The lure of constructing universality and humanism often meant that emphasis was on character nuances and character development and not so much on structural contexts. This is also true of Distant Thunder. The naturalistic treatment of famine in the film, Pathiraja and Hanan (2006, p.109) argue, "redirects its political engagement from the structural to phenomenological and toward a construction of Indian humanism." Robinson
(1989) has argued that the real theme of Distant Thunder is not the famine or starvation, rather human failures and moral awakening through adversity. The film is primarily invested in a Brahmin's moral journey and his subjectivity in the wake of the famine.

The conflict-ridden and oppressive nature of the caste system does not really find any substantive place in the narrative. Even when revealing some of the anomalies of the caste system becomes inevitable for Ray, it never arrives at a critical juncture.The question of the caste system is represented as a moral conundrum for Gangacharan and not as a harsh reality lived by so many. In Ray's imagination, all oppressed castes inhabit the village equally (Pathiraja and Hanan, 2006). Ray attempts to generate a sympathetic reading by according humanity to both the oppressor and the oppressed. With regards to the question of caste, the film suggests a moral adjustment instead of complete annihilation. Any reading of caste from the prism of humanism is bound to produce an understanding that is insufficiently contextualized.

In Ray's Distant Thunder, the only Dalit woman the audience meets is Moti who appears in brief spurts to highlight the humanity of the Brahmin protagonists and to testify to the restrictions of caste that these protagonists are meant to transgress by way of consummating their humanity. Moti is accorded a mere fraction of the total screen time and spoken parts within the film and is promptly relegated to the background when the narrative purpose of her appearance is met. Moti appears twice in the film. The first time we see her is when she visits Ananga; this sequence in the film is purposed with disclosing the class and caste difference, and informing the audience that the famine has started affecting the lives of people in some other parts of the region. The relationship between Ananga and Moti is marked by caste difference. Ray indicates it but is interested more in highlighting the 'feminine' bond. Caste is conveyed as a minor glitch, or inconvenience; a 'feminine' bond can allow for surpassing of marked 
caste-differences. The second time we see Moti is towards the end of the film. Moti comes to see Ananga in a desperate search for food at the end of her life. Ananga offers her food but famine induced starvation has made her so weak that she dies. Now lying in the open, the burden of cremating Ananga's untouchable friend is on Gangacharan - performing this task would mean polluting himself. Herein lies Gangachran's first act of redemption but curiously we never see it in the film. In the final shots, we see Gangacharan leaving his home to cremate Moti and then the film cuts to a famine-stricken Brahmin family of ten approaching the village. Adding to his redemption, the film shows Gangacharan's openness to accept the family despite his own worsening material situation. With regards to supporting ten additional individuals, Ananga corrects Gangacharan saying 'not ten, but eleven'. "Gangacharan's fatherhood is celebrated emblematically as well as domestically. He will father a stranger's family as well his own" (Cooper, 2000, p. 152). Story of the cycle of rebirth via Moti's death and the announcement of the expected baby seems to compound the erasure of Moti / the Dalit experience - not only is she there to prove Gangacharan's humanity, but she has to die in order for a 'higher' life to be (re)born. Ray's handling of Moti's character is emblematic of Brahmanical ideology; she is confined within a discourse of 'sympathy' and 'compassion'; she is a mute spectator; has no agency; is never angry with injustices; and above all is in service of rendering humanity to a Brahmin.

In reading this film I was particularly drawn to postcolonial-subaltern hermeneutics as it "provides with a critical apparatus and a register with which to best trace the liminal positions that Dalits occupy in India even today, as being both the past-in-the-present and the present-in-the-past of Indian historicity" (Haider, 2016, pp. 195-196). The postcolonial project of subaltern studies has enabled us to engage with the complexities of epistemological and ontological alterity and imagine a historiography that centers the alternative histories of subaltern resistance and consciousness. It has also enabled us to ask questions like how the agency, resistance, and consciousness of subalterns are presented and dealt with; who speaks; are subalterns just mute spectators; how is alterity performed; how is the radical heterogeneity of lived experiences of subalterns mediated; and most importantly who is standing in for whom? These questions assume even greater significance in light of how Nishat Haider has characterized Indian cinema. He argues that "In the Indian cinema, the inherent, dominant Brahminical ideology has helped preserve the power of the upper-caste Hindus, which sanctions them to secure the "free acceptance" of subjection via the interpellation of its "subjects"'" (Haider, 2015, p. 199). The task, then, is to deploy subaltern analytical and creative agency to interrogate and destabilize dominant ideas and this destabilization is a necessary, if not sufficient, condition for instating alternative, subaltern ways of being and knowing.

\section{Contracts of making, viewing and listening}

Contracts of making, viewing and listening treats Satyjit Ray's Distant Thunder as an archival site and is informed by a quest for reenactment of the archive to arrive at renegotiated and remediated readings, and ultimately to imagine new futures. It pulls its conceptual framework from Homi Bhabha's minority discourse that calls for intervention in the sovereignty of hegemonic discourses, responsible for nation's self-generation (Bhabha, 1990). For Bhabha, minority discourse is about putting forth contestatory narratives that reconstitute the nation as a social space that is "internally marked by cultural difference, the heterogeneous histories of contending peoples, antagonistic authorities, and tense cultural locations" (Bhabha, 1990, p.299). Once the performative spaces of multiple contending histories, especially subaltern histories, have intervened in the nation and its narration, the official (or dominant) archive reveals itself to be a repository of power. This intervention might not inscribe a history of the people, as Bhabha puts it, or create political solidarities but it certainly does not "celebrate the monumentality of historicist memory, 

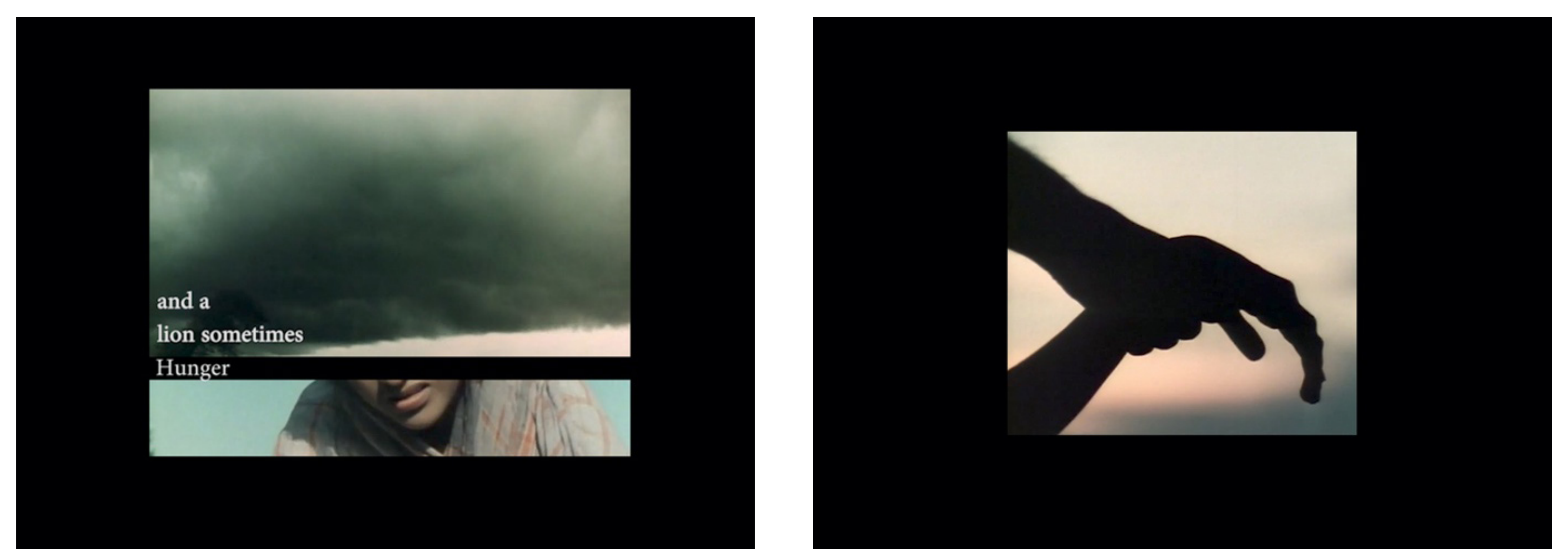

Fig. 1/2 Screenshot from Contracts of making, viewing and listening, 2019 (Weblink: https://vimeo.com/465384524 Password: contracts)

the sociological totality of society, or the homogeneity of cultural experience" (Bhabha, 2004, p. 225). Intervention, as articulated by Bhabha (2004), is a practice of enunciation (articulation, voicing, and emergence of discourse), inspired by the laudatory zeal of putting marginal - which often are contrapuntal, anachronistic, and antisystematic - narratives next to the dominant ones. In reference to, and as an extension of, Bhabha's usage of the term 'intervention', Haider (2015, p. 228) argues that "meaningful cinematic interventions offer an enabling method of the enunciation of the liminal status of the marginalized other in such a way that the "other half' of communication can enter the picture on an equal footing". In the spirit of enunciating the liminal status of the marginalized other, in Contracts of making, viewing and listening, which essentially is an intervention into Distant Thunder, I was motivated, at times, by finding traces of counter-memories in the film and building on them, and at other times, by putting them in dialogue with narratives emerging from marginal spaces to enable a renegotiated history of the famine. I was particularly inspired by Jong's (2016) formulation that re-enactment of the archive is needed to question the conditions of possibility of its own making. Furthermore, he argues that archives can be sites for performative reappropriations; by animating the archives we can not only displace the original logics of it but also perform alternative futures. In my intervention, I follow a range of strategies. Despite a myriad of theoretical influences and artistic strategies employed in my intervention, at the core, the desire is to pursue a double gesture of subalternity as both a theoretical paradigm (thinking) and a methodological stance (making) in film practices.

In the intervention, there is an attempt to let Dalit discourse inflect nation's Brahmanical self-generation. By generating readings of the famine from Dalit perspectives, the intervention seeks to make the narrative of the nation exceed its own boundaries. Contracts of making, viewing and listening acknowledges that the experience of the Famine as a totality is an unknowable and uncontainable multiplicity; even from the lens of Dalit consciousness there is no authentically 'true' story of the Famine. Despite this acknowledgement, without inserting the contestatory narratives arising from subaltern spaces it's unimaginable to destabilize the Brahminical ideology. The intervention is aimed at exploring - how that Dalit experience is erased or elided in existing representations and how to see the Famine through Dalit consciousness. As for the title of this intervention, by Contracts of making, viewing and listening, I mean epistemological and ontological conditions that allow a certain kind of representation of Dalits 
(question of making) and interpellation of spectators (question of modality of viewing and listening). The title suggests both the present condition and future imaginaries.

Moti's sub-narrative in Distant Thunder affected me deeply. She appears only twice in the film and has limited screen time and spoken parts. I began with locating and extracting the sequences where she has a narrative purpose. These clips were the first things on the editing timeline. I suppose I was responding to a very basic creative and analytical desire of asking what will happen if I prolong Moti's sub-narrative within the film by claiming the space and time that the original filmmaker did not deign to accord. This, in a way, became the first pre-determination for a transformative re-working of Distant Thunder. Parallelly, for the purpose of my larger research on the Bengal Famine, I had also been searching Dalit poetry on the subject. A friend of mine suggested Hunger - a poem written in Marathi by Dalit poet Namdeo Dhasal. Even though the poem is not directly about the Bengal Famine and written almost four decades later, but as the name suggests, it encapsulates so much about Dalit suffering and struggle. Unlike Ray's handling of Moti's character, the poem, while realistic, never evokes sympathy. The poem serves as a site of counter-memory and counter-archive; it is motivated by re-inscribing histories of Dalit worlds; and most importantly, realism invoked is already opening up the possibility of transformative politics. Moreover, the poem functions as a reminder of the perils of relegating the famine as an event from the past so as to avoid the moral conscience that it demands from us in the present. The poem had a profound impact on me and stayed with me. For the first few days of editing I was constantly thinking about creative and critical possibilities the poem will afford, and eventually I took the decision that working with poetry will be my second pre-determination.

Within this context I ended up with another poem titled Portrait of My Village by Tamil Dalit poet Sukirtharani. Distant Thunder alludes to caste realities but is not invested in critically exploring it, furthermore, the film generates an idealized and romantic notion of the rural. I wanted to unsettle this notion and was looking for Dalit poetry that specifically talks about Indian villages. I came across Sukritharini's poem in an academic article by Pramod K. Nayar (2015) where he mentions this poem in the context of Dalit poetry and traumatic materialism. Nayar (2015, p. 4) writes "She centres the body of the lower caste through visually evocative realist description, the realism conveying the material and corporeal harshness of everyday Dalit lives. This is the traumatic realism of the poem." Portrait of My Village, for its Dalit traumatic materialism, became a relevant text that I wanted to be in conversation with Ray's Humanism.

In Distant Thunder, Gangacharan's 'suffering' is either equated to or exemplified through the Dalit suffering of Moti. In foregrounding his Brahmin protagonists, Ray lets them stand in for the primary witnesses. In the film, Gangacharan is standing in for Moti and that means "erasing the crucial difference that is the very structure of their suffering-their experience, unique to them" (Haider, 2015, p. 213). I thought, this 'standing in' can be disrupted through these two poems as they name and contextualize the disavowal of faultlines of caste and moreover, represent a resistance against the opportunistic appropriation of Dalit experiences by upper-caste authors.

Since all three activities (reading, writing and making) were going parallelly and inflecting each other in a rhizomatic fashion, I cannot fathom charting out a chronological line - there were many detours, expected and unexpected encounters with materials, thinking, references etc. As a result, I ended up with some more texts and began experimenting with combining Dalit poetry, direct quotation from Ray, narrative commentary, and audiovisual quotation from Ray's film itself - in an effort to arrive at something artistically that provides a renegotiated reading of Distant Thunder but more importantly already contains/proposes, even if it's very tentative, a different epistemological, ontological and aesthetical imaginary. 
I wanted to place texts and images in proximity but was acutely aware of not establishing a hierarchy between the two. Based on my experience in filmmaking and my interest in poetry I have come to appreciate the plasticity between text and image - text can easily slide into the realm of image and image can easily slide into the realm of text, in other words, it's possible to write in/with/on/about/for/through images and create images in/with/on/about/for/through writing. Therefore, in making Contracts of making, viewing and listening, text and image were seen as non-dual onscreen acts that seek to perform research in and through cinema.

Part of the argument of performing research in and through cinema is also that it can't be a mere illustration of research (Grant, 2016) - it has to invest in both poetics (the question of form) and critical analysis (the question of content) so that it can stand on its own as a research expression. In light of this, in my intervention into Distant Thunder, I treated every onscreen act as montage creation where content and form are intrinsically hyphenated. I was constantly asking the question Carter (2004, p. xi) poses in the context of material thinking: "What is the material of thought?" I took it to mean that how is the research expressed on the screen. Based on my experience of making Contracts of making, viewing and listening I would argue that it's difficult to engage with material thinking without embracing the idea that it can only be arrived at tentatively and experimentally. Its only in and though rehearsals, errors, chance encounters, accidents, and repetitions that I could pursue thinking-making and making-thinking

In this transformative reworking of Distant Thunder, I chose to perform both internal and external montage. By recutting and rearranging certain portions from the film and putting them in conversation with materials that existed outside of it, I am simultaneously decontextualizing and recontextualizing Distant Thunder. Moti's sub-narrative needed to be decontextualized, distorted, and stretched in terms of screen time and space to enable a reading outside of humanism and to repurpose it with Dalit epistemologies and ontologies. In terms of its construction, especially the form my insights take in, Contracts of making, viewing and listening is geared towards, to borrow López and Martin's (2017) phrase, "setting the experience of simultaneity but leaving room for seemingly chance interactions between the screens to occur". This is achieved through a very careful consideration and choreography of onscreen acts taking place in and across texts, sounds, and images.

The desire to perform research in and though cinema meant engaging very meaningfully with the question of form. In Contracts of making, viewing and listening it has manifested through the fragmentation of the frame along vertical and horizontal lines, through various configurations of these fragmentations, through working at the borders of these fragmentations, through vast black portions of the frame, through experimentation with freezing, expanding, accelerating, and slowing screen space and time, through careful repetitions of some sounds, texts, and images, through unsettling the boundaries between titles and subtitles, poetry and commentary, utterances by the author in and outside of the film, through complete and incomplete articulations, and through planned and unplanned silences between those articulations. Also, the idea behind these formal strategies in my intervention was to, in a limited sense, reveal its own making - with the hope that it will bring the spectator closer to the performativity of research on the screen.

Since I was mobilizing a significant amout of text in my intervention, I had to be careful about 'doubling/mirroring'. López and Martin (2017), pointing to its pitfalls, warn us " one of the problems we see in much contemporary work is an obsession with doubling, to the point of sheer redundancy: what is said or written on screen, and what is shown via montage from the works being analysed, enter into a mirroring relation marked by a strict equivalency. The conventional primacy and authority accorded to 'the word' is thereby inevitably reinforced." This is why the image-text operations in my intervention is 


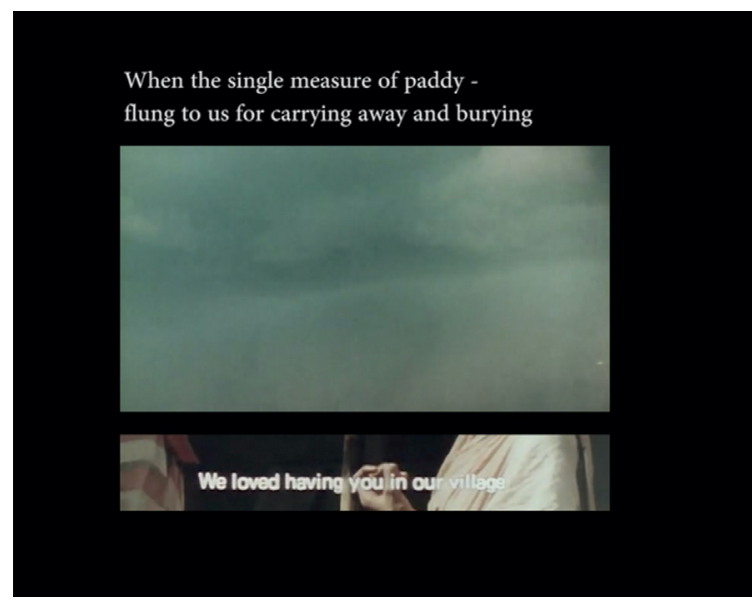

Fig. 3 Screenshot from Contracts of making, viewing and listening, 2019

geared towards juxtapositions, associations, disassociations, comparisons and assemblages. The attempt is to create an interplay between texts and images so that they emerge already inflected by each other and constantly exceed their individual expectations and meanings.

In line with the aim of my boarder research, which is to, by means of critical/practical exercises, move images towards subaltern epistemologies and ontologies, I had to be careful with regards to what my intervention into Distant Thunder proposes. As alluded earlier, whilst we might wish to understand a Dalit experience of the Famine, or to see the Famine through Dalit consciousness, we should resist the temptation of creating authentically 'true' stories of the famine. The claim of subaltern intervention is not to "truly and fully 'represent' the subaltern either in the sense of 'making them present again' or 'standing in for them"' (Chaterjee, 2010, as cited in Sircar, 2016, p. 32). The idea, rather, is to recognize subaltern narratives, like any other narrative, occur and operate in multiple registers and are often fragmentary. The aforementioned array of narrative strategies, especially forms, were deployed to engage with and facilitate this fragmentary nature. I wanted my intervention to make a genuine attempt to do what it says it wishes to do.

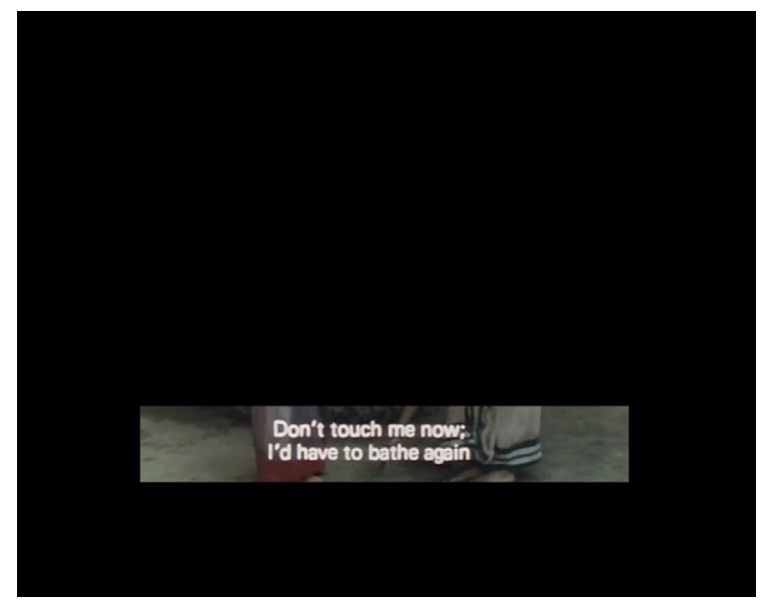

Fig. 4 Screenshot from Contracts of making, viewing and listening, 2019

\section{Final Considerations}

Through the making of Contracts of making, viewing and listening, and generally from the "perspective" of a filmmaker, I would argue that if we wish to establish artistic research in film as a field of study, methodology, or a scholarly form, we have to put the practice of film at the centre. Practice of film, with regards to research, is both a process and an outcome - it is a language through which the inquiry is both pursued and expressed. Film language provides us with the opportunity to make any research expression more than its written equivalent. Furthermore, a thoughtful consideration and mobilization of film language can enable these research expressions to be experienced, in its own right, as standalone/ self-contained scholarships. It's difficult for me to evaluate the extent to which Contracts of making, viewing and listening echoes López and Martin's (2017) formulation but it certainly summarizes its aspirations, interests, and motivations: "If we ask of a good written text that its construction is rich both in the insights it offers and in the form it takes, we must be ready to ask the same of audiovisual essays: that they exhibit and explore a genuinely audiovisual form." 


\section{References}

Banerjee, S. (2017, February 3). Focus on Ray's Cameraman. The Telegraph. Retrieved April 22, 2019, from https://www. telegraphindia.com/states/west-bengal/focus-on-ray-rsquos-cameraman/cid/1472976

Bhabha, H. (2004). The location of culture. Routledge.

Bhabha, H. (1990). DissemiNation: time, narrative, and the margins of the modern nation. In H. Bhabha (Ed.), Nation and Narration. Routledge.

Bolt, B. (2004, April). The Exegesis and the Shock of the New. TEXT Special Issue, 3. http://www.textjournal.com.au/speciss/ issue3/bolt.htm

Candy, L. \& Edmonds, E. (2018). Practice-based research in the creative arts: Foundations and futures from the front line. Leonardo, 57(1), 63-69. https://www.mitpressjournals.org/ doi/pdf/10.1162/LEON_a_01471

Carter, P. (2004). Material Thinking: The Theory and Practice of Creative Research. Melbourne University Publishing.

Chatterjee, P. (2010). Empire and Nation. Columbia University Press.

Cooper, D. (2000). The cinema of Satyajit Ray: Between tradition and modernity. Cambridge: Cambridge University Press.

Gibson, J. (Ed.). (2015). The Philosophy of Poetry. London: Oxford University Press.

Grant, C. (2019). Dissolves of passion: Materially thinking through editing in videographic compilation. In C. Keathley, J. Mittell, \& C. Grant (Eds.), The videographic essay: Practice and pedagogy. http://videographicessay.org
Grant, C. (2016, December 4). The audiovisual essay as performative research. NECSUS: European Journal of Media Studies. http://www.necsus-ejms.org/the-audiovisual-essay-as-performative-research/

Grant, C. (2014). The shudder of a cinephiliac idea? Videographic film studies practice as material thinking. ANIKI: Portuguese Journal of the Moving Image, 1(1), 49-62.

Gupta, U. \& Ray, S. (1982). The politics of humanism: An interview with Satyajit Ray. Cinéaste, 12(1), 24-29.

Haider, N. (2016). In quest of a comparative poetics: A study of Sadgati. In M. Asaduddin (Ed.), Premchand in world languages: Translation, reception and cinematic representations (pp. 195-196). Routledge.

Haider, N. (2015). Framing Dalit: A study of Satyajit Ray's Sadgati. South Asian Review, 36(1), 197-228.

Jong, F. D. (2016). At work in the archive: introduction to special issue. World Art, 6(1), 3-17.

Kaur, R. (2014). The vexed question of peasant passivity: Nationalist discourse and the debate on peasant resistance in literary representations of the Bengal famine of 1943, Journal of Postcolonial Writing, 50(3), 269-281.

López, C. A. \& Martin, A. (2017). Writing in Images and Sounds. Sydney Review of Books. Retrieved July 26, 2020, from https://sydneyreviewofbooks.com/essay/writing-in-images-and-sounds/

Minh-ha, T.T. (1991). When the Moon Waxes Red: Representation, Gender and Cultural Politics. London: Routledge.

Nayar, P. (2015). Dalit poetry and the aesthetics of traumatic materialism. Indian Journal of Gender Studies, 22, 1-14. 
Netherlands Film Academy. (n.d.) Artistic research. Retrieved July 21, 2020, from https://www.filmacademie.ahk.nl/en/ master-programmes/master-film/programme/artistic-research/

Pathiraja, D. \& Hanan, D. (2006). Center, periphery, and famine in Distant Thunder and In Search of Famine. In C. Fowler and G. Helfield (Eds.), Representing the rural: Space, place, and identity in films about the land. Detroit. Wayne State University Press.

Robinson, A. (1989). Satyajit Ray: The Inner Eye. London: I.B.Tauris

Sen, A. (1981). Poverty and famines: An essay on entitlements and deprivation. New York: Oxford University Press.

Sengupta, D. (2016, August). A metropolis of hunger: Calcutta's poetry of the famine. Coldnoon: International Journal of Travel Writing \& Travelling Cultures, 5(1). Retrieved August 15, 2017, from http://coldnoon.com/a-metropolis- of-hunger-calcuttas-poetry-of-the-famine-1943/

Sircar, S. (2016). Between the highway and the red dirt track: Subaltern urbanization and census towns in India [Unpublished doctoral dissertation]. Lund University.

Torlasco, D. (2016). House arrest. NECSUS. Retrieved June 15, 2020, from https://necsus-ejms.org/house-arrest/

Wood, R. (1971). The Apu Trilogy. New York: Praeger. 